\title{
LabTEC@: Um Ambiente para incentivar a produção de Recursos Abertos Educativos com os estudantes do Ensino Médio
}

\author{
Marcelo A. Corrêa ${ }^{1}$, Angelo Beck ${ }^{2}$ \\ ${ }^{1}$ Departamento de Processos Industriais - Campus Maceió - Instituto Federal de \\ Alagoas - (IFAL) \\ R. Mizael Domingues, 75 - Centro, 57020-600- Maceió - AL - Brazil \\ ${ }^{2}$ Grupo de Pesquisa em Redes Inteligentes (GPRI) - Campus Maceió - Instituto Federal \\ de Alagoas - (IFAL) - Maceió - AL - Braszil. \\ marcelo@gmail.com, angelobeck@gmail.com
}

\begin{abstract}
This article presents a learning environment experience for the production of Open Educational Resources (OER) with a focus on high school students integrated with vocational courses. Assuming that the younger generations assimilate more easily the cultural changes, this experience encourages the production of content for free knowledge to the strengthening the culture OER among teenagers of high schools public. Starting from the virtual and physic implementation of the one space called LabTEC@, a mixture Library, Video library and laboratory, high school students integrated into technical courses in Electrical and Electronic, are encouraged to produce open educational content, projects, products, experiments, movements and games on a virtual projects community supported on the computational platform called ECOLABORE, a open source platform too, which serves of the collaborative virtual environment.
\end{abstract}

Resumo. Este artigo apresenta uma experiência de ambiente de aprendizagem orientada para produção de Recursos Abertos Educativos (REA) com foco nos estudantes do ensino médio integrado à cursos profissionalizantes. Assumindo que as gerações mais novas incorporam mais facilmente mudanças culturais, esta experiência incentiva a produção de conteúdos de conhecimento livre para o fortalecimento de uma cultura em REA com adolescentes dentro da rede pública de ensino médio. Partindo da implementação de um espaço virtual e físico denominado de LabTEC@, uma mistura de Biblioteca, Videoteca e Laboratório, os alunos de ensino médio integrado à cursos técnicos nas áreas de Eletrotécnica e Eletrônica, são incentivados a produzirem conteúdos educativos abertos, projetos, produtos, experimentos, movimentos e jogos dentro de uma comunidade virtual de projetos apoiados sobre uma plataforma computacional denominada ECOLABORE, plataforma esta também em código aberto, que serve de ambiente virtual colaborativo.

\section{Introdução}

O Instituto Federal de Alagoas (IFAL), instituição que oferta educação profissional técnica de nível médio tem o desafio de trabalhar com alunos provenientes do ensino fundamental com deficiências de aprendizagem em português e matemática. 


\section{CBIE-LACLO 2015}

Anais dos Workshops do IV Congresso Brasileiro de Informática na Educação (CBIE 2015)

Como confirmam os dados dos resultados da Prova Brasil 2013 (http://www.qedu.org.br/brasil/aprendizado), onde em matemática, 11\% é a proporção de alunos que aprenderam o adequado na competência de resolução de problemas e, em português, é de $23 \%$ a proporção de alunos que aprenderam o adequado na competência de leitura e interpretação de texto, até o $9^{\circ}$ ano na rede pública de ensino. Tal cenário dificulta desenvolver conceitos, habilidades e competências necessárias a formação do técnico em eletrotécnica e eletrônica.

Segundo Dirksen ${ }^{1},(2011)$, o uso de tecnologia pode contribuir significativamente para aprendizagem. Neste sentido a idéia da criação de um espaço diferenciado das estruturas convencionais da escola, que contemple novos métodos e técnicas para aprendizagem e produção de conteúdos pode ser viável.

O perfil dos alunos do curso técnico integrado de eletrotécnica e eletrônica, do IFAL, campus Maceió, é caracterizado por adolescentes na faixa etária de 14 a 18 anos que fazem uso intensivo de aparatos tecnológicos como games, tablets, smartphones e notebooks. Como defende Meyer e Rose2 (2014) em seu livro "Universal Design for Learning", a aprendizagem mediada pelas novas tecnologias da comunicação e informação ocorre na interação dinâmica entre os estudantes, o ambiente de aprendizagem e o contexto, de forma dinâmica e complexa. Para o autor, as ferramentas tecnológicas fazem parte do ambiente de aprendizagem, e, para tanto, tais ambientes devem ser concebidos de tal forma que promovam a interação e a colaboração entre os envolvidos no processo de aprendizagem.

Partindo da definição de Educação Aberta como sendo o de fomentar (ou ter a disposição) por meio de práticas, recursos e ambientes abertos, variadas configurações de ensino e aprendizagem, mesmo quando essas aparentam redundância, reconhecendo a pluralidade de contextos e as possibilidades educacionais para o aprendizado ao longo da vida, Amiel,(2014), e compactuando com a crença de que todos devem ter a liberdade de usar, personalizar, melhorar e redistribuir os recursos educacionais, sem restrições, conforme sugere a Declaração da Cidade do Cabo (2007). É que foi criado o ambiente LabTEC@, um espaço híbrido que aglutina recursos de laboratório eletroeletrônico, com várias plataformas de software e hardware dando preferência para licenças de código aberto, como Arduino, Linux, LibreOffice, e com um ambiente virtual desenvolvido especificamente para criação de uma comunidade de projetos, de modo a disponibilizar aos estudantes de ensino médio as mais variadas formas para que manifestem suas idéias e projetos, colocando-os na Web sob a condição de licenças abertas.

\section{LabTEC@ como ambiente híbrido de ensino e aprendizagem}

O ambiente LabTEC@ é uma tentativa dialógica em que as configurações de ensino e aprendizagem emergentes coexistem e ao mesmo tempo desafiam a lógica e a estrutura da escola, respaldando assim o conceito de Educação Aberta, Amiel, (2012).

Não se trata de um projeto de extensão ou de pesquisa atrelado aos editais institucionais de fomento, mas sim de um ambiente de ensino e aprendizagem híbrido que oscila entre o espaço da instituição oficial de ensino, o espaço virtual e o espaço onde o aluno efetivamente conduz seu projeto, aproximando-se do modelo "e-service", Amiel e Herrginton, (2012). 


\section{CBIE-LACLO 2015}

Anais dos Workshops do IV Congresso Brasileiro de Informática na Educação (CBIE 2015)

O espaço físico que caracteriza o ambiente LabTEC@é uma sala com 56m² que fica situada dentro do prédio do Curso Técnico de Eletrônica do Campus Macéio do IFAL. Este espaço combina um ambiente de biblioteca com videoteca e laboratório de práticas em eletrônica e eletrotécnica, contemplando novos métodos e técnicas para aprendizagem e produção de conteúdos educativos.

Com um pequeno acervo de livros e periódicos nas áreas de eletro-eletrônica e as que compõem o currículo do ensino médio, o espaço pode ser visto como uma biblioteca em que alunos engajados na comunidade acessam a qualquer momento não só recursos bibliográficos mas também recursos multimídias. Com um acervo de 50 filmes nacionais, disponibilizados pelo MEC em parceria com Ministério da Cultura provenientes do programa Cine Educação, o espaço caracteriza-se como videoteca, mas disponibiliza também equipamentos, instrumentos de medição, componentes eletroeletrônicos, ferramentas e materiais de consumo como um laboratório de práticas em eletricidade e eletrônica, aproximando-se de uma estrutura como Fab-Lab, onde a cultura do "faça-voce-mesmo" é incentivada e orientada para uma produção colaborativa, Neil (2012).

Este espçao físico diferencia-se da estrutura convencional da escola, tanto no aspecto físico quanto na operacionalização, pois é a própria comunidade de alunos e professores que voluntariamente se engajam no zelo do espaço, cuidando da organização e do controle de acesso, que se dá por intermédio de uma entrevista com o professor voluntário que coordena a LabTEC@, o qual apresenta ao novo membro todos os princípios e normas de funcionamento da comunidade de projetos.

Como espaço virtual, a LabTEC@ é um ambiente de produção de conteúdo digital que implementa uma interface para criação de domínios, construção e publicação de páginas na Web de forma simples, sem a necessidade de apropriação de habilidades em linguagens de programação como Java, PHP ou HTML.

Este espaço funciona como um portal para criação de páginas, de forma gratuita para os membros inscritos, que ganham um login e uma senha para o acesso ao ambiente permitindo que o interagente monte blogs, páginas, banco de imagens, banco de dados bibliográficos e chat. Com isto, cada aluno inserido em um projeto específíco desenvolve seu trabalho adicionando conteúdos em um espaço virtual e pessoal de maneira livre, sendo que os membros que compõem a comunidade de projetos são incentivados a transformarem suas aprendizagens, produtos, montagens ou vivências em conteúdos educativos abertos.

\section{Um Ambiente para incentivar a produção de Recursos Abertos Educativos com os estudantes do Ensino Médio}

O objetivo maior do ambiente LabTEC@ é contribuir para a melhoria da aprendizagem no contexto do ensino médio de forma interdisciplinar, integrando conhecimentos técnicos na área de eletrônica e eletrotécnica com as outras área que compõem a grade curricular do ensino médio, disponibilizando e incentivando a produção de Recursos Educacionais Abertos orientados à este público.

Por meio de roteiros de experiências, esquemas para construção de protótipos, códigos fonte, artigos, vídeos e apostilas produzidas pelos próprios alunos sob tutoria de 
professores voluntários, o ambiente virtual da LabTEC@, configura-se como um repositório de saberes do tipo "faça-você-mesmo", próximo ao modelo do Open Source Eletronic Projects (http://www.open-electronics.org), porém orientado à alunos de ensino médio integrados aos cursos técnicos profissionalizantes na área de eletricidade $\mathrm{e}$ eletrônica.

Caracterizar-se como repositório de saberes com reputação é uma meta perseguida por todos os membros da LabTEC@, por isto adotou-se uma metodologia para sistematização da produção e divulgação dos recursos educativos produzidos.

O gerenciamento do conteúdo, bem como o das seções que são criadas e modificadas no site da LabTEC@, é feito por um núcleo gestor virtual formado pelas lideranças de cada célula de trabalho (alunos e professores envolvidos nos projetos específicos em execução), que de forma sociocrática decidem a estrutura do site principal, considerando sua usabilidade e o foco na área do ensino médio e técnico.

Desta forma cada aluno inserido em um projeto específico desenvolve seu trabalho adicionando conteúdos em seu site pessoal, e com auxílio de um tutor decide o que será compartilhado e disponibilizado no site da LabTEC@, de modo a manter um compromisso com a qualidade do que é produzido.

Ao configurar como publico, um determinado recursos de seu site pessoal, o interagente permite que a página principal da LabTEC@ mapeie de forma automática os conteúdos acrescentando-os ao site (http://www.labteca.ecolabore.net) que atua como um canal concentrador e organizador dos recursos, disponibilizando-os para o acesso público.

Toda a estrutura virtualda LabTEC@ funciona sob uma plataforma de software denominada Ecolabore, que suporta uma série de funcionalidades para a construção e operação deste ambiente.

O Ecolabore, é um software de código aberto, GPL, livre de quaisquer restrições de uso, que pode ser implementado sob qualquer servidor Internet. Idealizado e desenvolvido continuamente por Angelo Beck, um aluno formado no Curso Técnico de Eletrônica do IFSC, com apoio de uma rede de colaboradores, o software está em continuo aperfeiçoamento e pode ser acessado no endereço http://www.ecolabore.net/.

Com a plataforma Ecolabore é possível a criação e o gerenciamento de subdomínios de forma rápida e segura, o que permite assim criar domínios específicos para cada usuário que terá condições de manter sua autonomia sob o que e como publicar. Cada usuário pode selecionar a seção específica de seu site que irá contribuir com o conteúdo dentro do concentrador LabTEC@. Assim o site principal (http://www.labteca.ecolabore.net) cresce de forma automática quando seus membros adicionam conteúdos em suas páginas pessoais.

\section{Considerações finais}

Atualmente a LabTEC@ está aplicada aos Cursos Técnicos de Eletrotécnica e Eletrônica do IFAL-Campus Maceió, permitindo que alunos de Ensino Médio integrado a formação profissional técnica e tecnológica possam utilizá-lo em seu processo de aprendizagem. 


\section{CBIE-LACLO 2015}

Anais dos Workshops do IV Congresso Brasileiro de Informática na Educação (CBIE 2015)

As contribuições pedagógicas do uso do ambiente LabTEC@ foram perceptíveis nestes dois últimos semestres (2014-2 e 2015-1) onde se constatou um aumento do interesse e da participação dos alunos nas discussões realizadas em sala de aula, bem como o questionamento por eles sobre o que vem a ser um Recurso Educativo Aberto de qualidade que contribua significativamente para a aprendizagem no ensino médio.

O uso efetivo por parte dos alunos quanto ao ambiente, medido pelo número de acesso e atualizações, demonstra que a construção de conteúdos implica na assimilação de temas trabalhados em sala de aula, confirmando que a estratégia de incentivo à produção de conteúdos educativos abertos contribui na melhoria do processo de aprendizagem.

O trabalho colaborativo também se mostrou como um mecanismo essencial no processo, principalmente quando o projeto implica em prototipação, onde as montagens resultam basicamente da integração de componentes modulares já desenvolvidos em outros projetos. A reutilização de códigos e a modificação de partes mecânicas, elétricas e eletrônicas desenvolvidas em outros trabalhos caracterizaram bem o reúso na prática, permitindo a percepção da importância das licenças livres.

Até o final de 2015 pretende-se expandir o espaço virtual para mais dois pontos dentro da Rede Federal de Ensino Técnico e Tecnológico, contando com a participação de um concentrador no Sul do Brasil, dentro do IFSC e outro no Paraná dentro do IFPR, buscando formas de divulgação e colaboração para o aprimoramento e manutenção dos conteúdos disponibilizados.

Como defende Tel Amiel. "Não se trata portanto de pensar em quais novas mídias, sistemas ou técnicas podem suplantar modelos de ensino vigentes. Neste fértil e produtivo embate entre modelos sedimentados e emergentes, encontram-se oportunidades para configurações cada vez mais complexas de ensino e aprendizagem, que possam satisfazer a real diversidades de alunos e professores, nos mais variados contexto e condições." (Amiel, 2012),

\section{References}

${ }^{1}$ Dirksen, John, (2011) “ Design for How People Learn”, Editora New Riders, US

${ }^{2}$ Meyer, A. \& Rose, D. H. (2014) "Universal Design for Learning:Theory and Practice, CAST Professional Publishing. EUA.

Amiel, T. and Herrington, J. (2011) "Authentic tasks online: Two experiences". In: Olofsson, A.D. and Lindberg, J.O., (eds.) Informed design of educational technologies in higher education: Enhanced learning and teching. IGI Global, Hershey, PA, pp. 152-165.

Amiel, T. (2012) "Educação aberta: configurando ambientes, práticas e recursos educacionais", In: REA: Práticas colaborativas e políticas públicas. Santana, B., Rossini, C., Pretto, NL (org.) São Paulo: Casa da Cultura Digital

Neil, G. (2012) How to Make Almost Anything: The Digital Fabrication Revolution. In: Foreign Affairs (91), pp. 43-57, disponível em http://cba.mit.edu/docs/papers/12.09.FA.pdf. 